\title{
Linha do cuidado ao idoso na atenção primária à saúde: uma perspectiva das açóes da terapia ocupacional
}

\author{
Cassio Batista Alves ${ }^{a}$, Grasielle Silveira Tavares Paulin ${ }^{\mathrm{b}}$ \\ aUniversidade Federal do Triângulo Mineiro - UFTM, Uberaba, MG, Brasil. \\ ${ }^{b}$ Universidade de Brasília- UnB, Brasília, DF, Brasil.
}

\begin{abstract}
Resumo: No Brasil, a terapia ocupacional (TO) foi regulamentada em 1969 e, na década de 1990, se inseriu na Atenção Primária à Saúde (APS). Nesse nível assistencial, a TO atende diversas fases do desenvolvimento humano, inclusive o envelhecimento, que, em uma perspectiva de linha de cuidado e envelhecimento ativo, busca otimizar as oportunidades para a saúde, a participação e a segurança, utilizando-se os raciocínios clínicos em vista de planejar, orientar, realizar e refletir suas ações na produção da linha de cuidado. Como área de conhecimento, essa profissão considera as atividades humanas como parte da construção do próprio homem e busca entender as relações que esse homem, em atividade, estabelece em sua condição de vida e saúde. Os objetivos deste estudo foram verificar as ações e identificar a linha do cuidado na assistência da terapia ocupacional com idosos, na APS. Trata-se de uma pesquisa qualitativa, que utilizou uma entrevista semiestruturada aplicada no período de abril a maio de 2013, com seis terapeutas ocupacionais que atendiam idosos na APS do município de Uberaba-MG. Os dados foram analisados a partir da técnica do Discurso do Sujeito Coletivo (DSC). Observou-se que as ações da TO na produção da linha do cuidado à saúde do idoso se dão a partir do atendimento com a população, seja por meio de grupos ou individual, com a equipe durante discussões de casos, encaminhamentos ou gestão do trabalho. Essas ações se dão no território durante o diagnóstico territorial e a construção de redes, todas permeadas pelos princípios de equidade, integralidade, intersetorialidade e raciocínio clínico em TO.
\end{abstract}

Palavras-chave: Atenção Primária à Saúde, Idoso, Terapia Ocupacional.

\section{Primary health care to elderly people: Occupational Therapy actions perspectives}

\begin{abstract}
In Brazil, Occupational Therapy (OT) was legislated in 1969, and was introduced into the Primary Health Care (PHC) in the 90s. At this level of care, the OT serves various stages of human development, including aging, in a perspective of care and active aging line, seeks to optimize opportunities for health, participation and safety, using clinical reasoning in order to plan, guide, conduct and reflect their actions in producing the line of care. This career considers human activities as part of the construction of the man himself as an expertise area and seeks to understand the relationships that the active human establishes in its life and health. This study aimed to verify the actions and identify the occupational therapy line of care with the elderly in APS. This is a qualitative study that used a semi-structured interview applied during April to May 2013 with six occupational therapists that cared for older people in the APS at Uberaba-MG. The data was analyzed using the Collective Subject Discourse (CSD) technique. We observed that the OT actions to produce line of care for the elderly happen according to the general public care, whether individual or group, with the team during case discussions, referrals or work management and the territory during the territorial diagnosis and networks formation, all permeated by the principles of fairness, integrity, intersectoriality and clinical reasoning in OT.
\end{abstract}

Keywords: Primary Health Care, Elderly, Occupational Therapy.

Autor para correspondência: Cássio Batista Alves, Centro Integrado de Terapia Ocupacional, Avenida Santos Dumont, $1476,3^{\circ}$ Piso, CEP 38050-400, Uberaba, MG, Brasil, e-mail: cassioalvesto@yahoo.com.br

Recebido em Out. 30, 2013; $1^{\text {a }}$ Revisão em Abr. 08, 2014; $2^{\text {a }}$ Revisão em Abr. 30, 2014; $3^{\text {a }}$ Revisão em Maio 19, 2014 ; Aceito em Jun. 20,2014 


\section{Introdução}

A história da terapia ocupacional (TO) se inicia em 1917, quando um grupo de profissionais, entre médicos, enfermeiras, arquitetos, assistentes sociais e outros, se reuniu pela ideia de que a ocupação poderia desempenhar um importante papel na cura e na saúde (GORDON, 2011). No Brasil, a TO foi regulamentada em outubro de 1969 (CONSELHO..., 1969) e tem conquistado novos espaços de atuação além da área da saúde, inserindo-se também na educação e na assistência social.

A terapia ocupacional, como área de conhecimento, tem suas açóes voltadas para os problemas do homem em sua vida de atividades, ou seja, considera as atividades humanas como parte da construção do próprio homem e busca entender as relaçôes que esse homem em atividade estabelece em sua condição de vida e saúde (MEDEIROS, 2003). Nessa perspectiva, sua intervenção está alinhada à proposta de que o profissional deve desenvolver a capacidade de ajudar pessoas na obtenção da qualidade de vida que precisam e desejam ter, e não só combater doenças, contribuindo no fortalecimento dos processos de autonomia, desejos e possibilidades de transformar a si e ao seu contexto, de maneira que a doença ou a alteraçáo na funcionalidade, mesmo sendo um limite, não as impeça de viverem outras experiências na sua vida de modo prazeroso (BRASIL, 2009).

A TO na APS é datada desde os anos 1990, quando passou a fazer parte das Unidades Básicas de Saúde (UBS), atendendo pessoas com deficiências e incapacidades, entre outros agravos à saúde (ROCHA; SOUZA, 2011). Em 2008, a profissão passou a compor as equipes dos Núcleos de Apoio à Saúde da Família (NASF), tendo como objetivo ampliar a abrangência e o escopo das açóes da APS, e a resolubilidade da Estratégia de Saúde da Família (ESF) (BRASIL, 2008a). Nesse nível de assistência, a ação da TO compreende um conjunto de esforços dirigidos ao indivíduo e seu contexto, buscando utilizar os recursos e estratégias comunitárias para proporcionar o desenvolvimento de habilidades e competências para sua inserção e manutenção no meio social (NEISTADT, 2008).

Entre as açôes da TO na Atenção Básica, estâo os atendimentos à saúde da populaçáo nas diversas fases do desenvolvimento humano, inclusive o envelhecimento, que, em uma perspectiva de linha de cuidado e envelhecimento ativo, a TO busca otimizar as oportunidades para a saúde, a participaçáo e a segurança, utilizando os raciocínios clínicos em vista de planejar, orientar, realizar e refletir suas ações na produção da linha de cuidado (WORLD, 2005; SCHELL, 2008).
Ainda, segundo Merhy e Cecílio (2003), a linha de cuidado pode ser expressa na produção da saúde de forma sistêmica, a partir de redes macro e microinstitucionais, em processos extremamente dinâmicos. O Ministério da Saúde define a linha de cuidado como modelos de atenção que interagem açôes de promoção, prevenção, vigilância e assistência, voltados para as especificidades de diferentes grupos ou pelas necessidades individuais, o que permite, não apenas a conduçấo oportuna dos pacientes pelas diversas possibilidades de diagnóstico e terapêuticas, como também uma visão global das condições de vida (BRASIL, 2008b). Ou seja: pressupóem uma resposta global dos profissionais envolvidos no cuidado, superando as respostas fragmentadas. A implantação da linha de cuidado deve ocorrer a partir das unidades da APS, que têm a responsabilidade da coordenação do cuidado e do ordenamento da rede (BRASIL, 2010). Já Franco e Magalhães Junior (2003) sugerem que a linha de cuidado pode ser considerada como o percurso que um sujeito realiza na rede de saúde, incluindo serviços náo necessariamente do setor da saúde, como, por exemplos, aqueles oferecidos por entidades comunitárias e de assistência social.

Assim, o presente estudo tem como objetivo verificar as açóes e identificar a linha do cuidado na assistência da terapia ocupacional com idosos na Atenção Primária à Saúde.

\section{Metodologia}

\subsection{Amostra e critérios de inclusão e exclusão}

A pesquisa contou com a participação de seis terapeutas ocupacionais, a partir dos seguintes critérios de inclusão: tais profissionais deveriam ser formados, no momento da pesquisa, há, pelo menos, seis meses; atender à população idosa na atenção primária; aceitar participar da pesquisa, e responder à entrevista semiestruturada. Foram eliminados da pesquisa os demais profissionais que não se enquadravam nesse perfil. Destaca-se que os seis participantes da pesquisa representam todos os terapeutas ocupacionais que atendem à população idosa na APS, no município de Uberaba-MG.

\subsection{Local}

A pesquisa foi realizada no município de Uberaba-MG, onde a população idosa representa 12,5\% (INSTITUTO..., 2012). 


\subsection{Instrumentos para coleta de dados}

O instrumento foi elaborado pelos pesquisadores e buscou compreender suas ações com a população idosa na APS. As açóes se referiam àquelas do período de 2011 a 2012.

$\mathrm{O}$ instrumento autoaplicado de pesquisa foi entregue aos entrevistados e respondido após um mês ${ }^{1}$.

\subsection{Procedimentos para análise dos dados}

Para análise dos dados, utilizou-se o Discurso do Sujeito Coletivo (DSC) (LEFÉVRE; LEFÉVRE, 2006), sendo esta uma metodologia qualitativa que se preocupa em permitir a discursividade dos processos mentais de uma coletividade, por meio de discursos-síntese de sentidos semelhantes emitidos pelas pessoas; é composto por quatro operaçôes: ideias centrais, expressōes-chave, ancoragens e discurso do sujeito coletivo. Assim, o uso do DSC permite obter o pensamento coletivo, preservando a natureza discursiva. Assim, foi realizada a transcrição dos dados e observado que, nos discursos, havia semelhantes temáticas.

Quanto aos procedimentos técnicos para a organização das narrativas dos terapeutas ocupacionais, as etapas adotadas foram:

1. Leituras sucessivas das narrativas registradas.

2. Organizaçáo dos discursos, ou seja, com os discursos já digitados, selecionaram-se, por meio de uma nova leitura, quais eram as ideias centrais provisórias e suas respectivas expressôes-chave. Adotou-se um esquema de marcação com cores diferentes para delimitar as ideias centrais e as expressôes-chave.

3. As ideias centrais provisórias foram agrupadas em torno de uma mesma temática e dispostas segundo grandes temas.

4. A relação das ideias centrais foi reavaliada e aquelas que apresentavam semelhança de sentido eram agrupadas a fim de evitar redundâncias.

5. Finalmente, o discurso-síntese, com os sujeitos-coletividade "discursando" seus pensamentos sobre as diversas açóes da terapia ocupacional com idosos na APS de Uberaba-MG.
Ainda, foram utilizadas variáveis quantitativas para descrever o perfil sociodemográfico da população assistida pelos terapeutas ocupacionais.

\section{Resultados e discussão}

A partir da análise dos dados, foi possível fazer o levantamento do perfil sociodemográfico dos idosos assistidos e das açóes na produçáo da linha de cuidado e suas consequências.

\subsection{Perfil sociodemográfico dos idosos}

No levantamento do perfil sociodemográfico dos idosos, $60 \%$ dos entrevistados afirmaram que há maior prevalência de idosos entre 60 e 69 anos, enquanto que, nos atendimentos e visitas domiciliares, respectivamente, $80 \%$ e $100 \%$ dos entrevistados afirmaram que a prevalência se dá entre os idosos de 70 a 79 anos. Tais dados permitem refletir que os cuidados à saúde nos serviços ocorrem, também, a partir das condições de acesso, ou seja, os idosos mais ativos acessam o serviço de forma autônoma, enquanto os idosos mais longevos e, possivelmente menos ativos, necessitam do acompanhamento domiciliar para ter acesso ao serviço de saúde.

Quanto ao gênero, níveis de escolaridade e renda familiar de maior prevalência, os dados encontrados corroboram com o descrito por Silva et al. (2011), que, em sua pesquisa, apontam que as mulheres utilizam mais o serviço de saúde, se comparado com os homens; que o nível de escolaridade de maior prevalência está entre 0 e 7 anos, e que a os usuários que mais utilizam os serviços são os de baixa renda familiar. Note-se que o instrumento de pesquisa aplicado não é sensível para captar o número de idosos para análise descritiva; o instrumento questiona ao entrevistado a maior prevalência. Destaca-se que os resultados apontados neste trabalho referem-se às açóes da terapia ocupacional na APS no município de Uberaba-MG e cabe ressaltar que por haver poucos terapeutas ocupacionais distribuídos nos serviços, houve uma limitaçáo na amostra, o que impossibilita a generalização dos dados.

\subsection{Ações na produção da linha de cuidado}

A partir do DSC a seguir descrito, é possível observar que as açôes da TO na produção da linha do cuidado estão em consonância com os princípios do SUS. 
Contribuo na produção da linha de cuidado quando além de contemplar os princípios da integralidade na saúde em suas diferentes dimensóes, considero a intersetorialidade, ou seja, acompanho todo o processo de cuidado de forma integral e intersetorial, compreendendo que o processo acontece em rede com fluxos e hierarquizaçôes; faz-se necessário reconhecer e qualificar as "porta de entrada", seja nos hospitais, UBS ou pronto atendimento (participantes do DSC).

Assim, é possível observar que as açôes, nesse sentido, iniciam-se em qualquer ponto do sistema que opere a assistência, tais como no atendimento domiciliar, na equipe de saúde da família, nos serviços de urgência, consultórios, ou seja, em qualquer ponto onde haja interação entre o usuário e o profissional de saúde (MALTA; MERHY, 2010; MERHY; CECÍLIO, 2003).

Em um estudo realizado por Reis et al. (2012), foi identificado que uma estratégia fundamental para lidar com as necessidades de saúde da população é a organização dos processos de trabalho a partir das diretrizes das linhas de cuidado, pautados através da escuta e da reflexão sobre as necessidades dos sujeitos, priorizando o contato entre os profissionais, os usuários e a realidade do contexto social vivido. As linhas do cuidado, nesse sentido, contribuem não apenas para gestão do cuidado, como também na reorganização dos saberes e práticas do campo da produção da saúde (GALHEIGO, 2008).

A Figura 1 busca sistematizar as açóes da terapia ocupacional na produção da linha de cuidado, seus resultados e os princípios norteadores deste processo.

As açóes na produção da linha de cuidado encontradas a partir da análise dos dados foram as açôes com a população (atendimentos grupal e individual), açôes com a equipe (discussão de casos, encaminhamentos e gestão no trabalho) e açôes no território (diagnóstico territorial e construção de redes). Tais açôes serão apresentadas no decorrer da discussão juntamente com os princípios de Equidade, Integralidade, Intersetorialidade e Raciocínio Clínico, pois se entende, a partir das análises dos dados, que esses princípios permearam as ações do terapeuta ocupacional.

\subsubsection{Ações com a população}

Considerando-se o aumento da expectativa de vida e, consequentemente, do número de idosos, faz-se necessário o desenvolvimento de estratégias que visem à educação, à prevenção e à promoção da saúde, com vista na autonomia e na independência destes sujeitos (BITTAR; LIMA, 2011). Nos atendimentos grupais, as açôes da terapia ocupacional abrangem 462 idosos, que são assistidos semanalmente em

\section{AÇÓES DA TERAPIA OCUPACIONAL NA PRODUÇÃO DA LINHA DO CUIDADO}

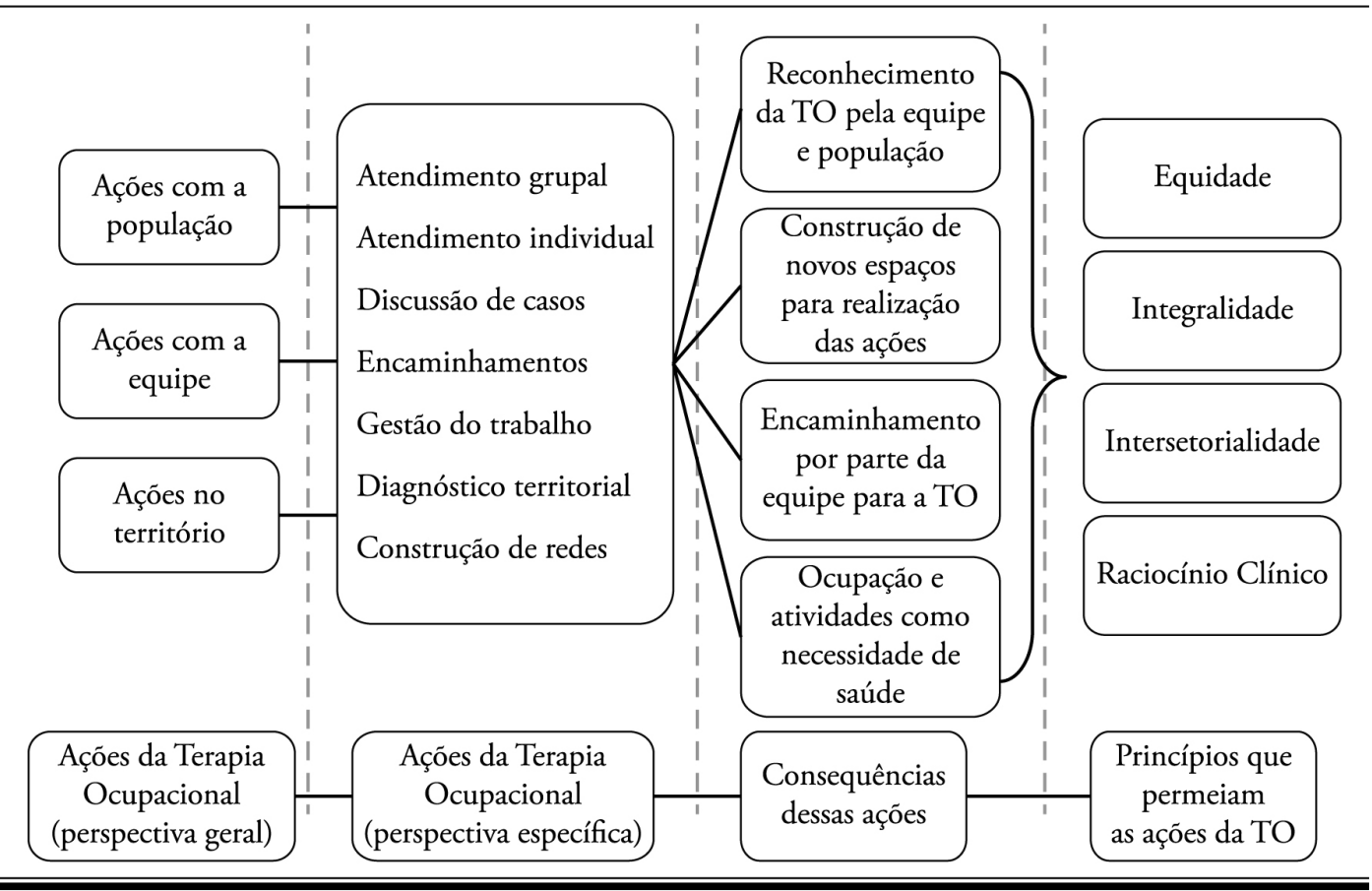

Figura 1. Ações da terapia ocupacional da produção da linha do cuidado. 
17 grupos, sendo que dez grupos são de caráter educativo, seis grupos são de caráter terapêutico e um grupo de caráter educativo e terapêutico, simultaneamente. Relacionados às áreas de ocupação, os objetivos da terapia ocupacional envolveram, principalmente, a Participação Social, as Atividades Instrumentais de Vida Diária (AIVD) e o Lazer; enquanto relacionados às habilidades de desempenho, os objetivos envolveram as habilidades sociais e de comunicação; a regulação emocional; as habilidades cognitivas, e práxica e motora.

É entendido que o homem participa de vários grupos durante as etapas da vida, tais como os grupos no trabalho, na família ou na comunidade; mas, com o processo de envelhecimento, os idosos tendem a romper e se afastar de alguns desses grupos (BITTAR; LIMA, 2011), tendo uma perda em atividades significativas. Sendo assim, o terapeuta ocupacional compreende a atividade grupal como potente intervenção na ascensão da participação social, o que interfere nas demais relaçôes do sujeito e em sua própria condição de saúde. Além disso, o grupo tem o potencial de facilitar o vínculo entre os profissionais de saúde com os usuários e interfere, positivamente, na adesão ao tratamento e nas medidas de prevenção (GARCIA et al., 2005).

Já no levantamento das açóes desenvolvidas no cuidado individual, observou-se que a terapia ocupacional atende a 48 idosos, sendo que 32 deles fazem parte de atendimentos domiciliares, enquanto 16 idosos são acompanhados a partir de visitas domiciliares. Os encaminhamentos se deram devido a quadros de depressão, dificuldade parcial na realização de atividades, dependência total na realização de atividades, por sequelas de doenças, participaçáo social afetada, restrição ao leito, necessidade de intervenção com cuidador, interesse no resgate e envolvimento de atividades, maus tratos, dificuldades de memória e realização de atividades produtivas. Os objetivos envolveram, principalmente, as áreas de ocupaçóes das Atividades de Vida Diária (AVD), Lazer e Participação Social.

Entende-se como atendimento domiciliar, atividades profissionais realizadas diretamente no domicílio das pessoas, envolvendo o cliente e a família, enquanto visita domiciliar possui caráter mais pontual, sendo que o profissional observa o contexto e realiza as devidas orientaçôes (LACERDA et al., 2006). Essas açóes são importantes, pois têm um cunho pautado na universalidade do acesso, garantindo a assistência à saúde, mesmo aos usuários que não têm acesso.

Ainda, as açôes são permeadas pelos raciocínios clínicos em terapia ocupacional, tais como o raciocínio narrativo, que busca compreender a história de vida dos sujeitos atendidos, e o raciocínio pragmático, que se refere à consideraçáo do terapeuta ocupacional sobre os fatores que limitam ou facilitam as intervençôes, sendo que tais açóes influenciam o processo terapêutico. Assim, as açôes na produção do cuidado na perspectiva de linha de cuidado acontecem no decorrer dos atendimentos da terapia ocupacional, sejam nos atendimentos grupais ou individuais; o cuidado se dá na atenção à saúde ocupacional, no fazer humano e, como supradescrito, nas ocupaçóes e habilidades de desempenho.

\subsubsection{Ações com a equipe}

Durante as açóes com a equipe, o terapeuta ocupacional tem buscado participar de discussōes de casos e reunióes de equipe, realizando encaminhamento, referência e contrarreferência, e participando na gestão do trabalho.

Nas açôes de discussóes de casos e reunióes de equipe, é entendido, por esse profissional, que, durante o cotidiano no trabalho, as reuniōes de equipe são importantes dispositivos para a estruturação, a organização, a informação, o estabelecimento de diretrizes e o espaço de tomada de decisóes. Estes autores ainda afirmam que são nestes momentos que são emersos suas especificidades enquanto sujeitos de diferentes contextos e que precisam se relacionar (GRANDO; DALL'AGNOL, 2010).

Os benefícios das reuniōes de equipe devem ser realçados, sendo uma oportunidade para ocorrer a socializaçáo do conhecimento, o planejamento conjunto e os subsídios para tomadas de decisóes mais assertivas (DALL'AGNOL; MARTINI, 2003). Essas questóes vão ao encontro com o discurso coletivo, quando os profissionais relataram que:
Sabendo da importância da discussäo de casos clínicos e reunióes de equipe para integralidade do cuidado e consequente melhora das condiçóes de saúde da população, convido os profissionais para discussão e acompanhamento dos casos que atendia. Mesmo com a dificuldade de horário com a equipe, insisto e solicito, sempre que necessário tais reuniöes para discussão de casos, pois compreendo sua relevância (participantes do DSC).

Nota-se, a partir do discurso coletivo, que a participação de todos os profissionais nas reuniōes de equipe são tarefas difíceis de serem concretizadas na prática de alguns serviços; porém, verifica-se a necessidade dessa ação e da competência desse profissional perante a habilidade de se comunicar. Em um estudo realizado por Witt (2005), comunicação 
apropriada entre profissionais se constitui como componente indispensável para o desenvolvimento de interaçôes sólidas no contato direto não apenas com os clientes, como também no trabalho em equipe, administrativo e gerencial.

Entende-se que as discussóes de casos ou estudos de caso, quando em uma perspectiva interdisciplinar, de desenvolvimento de atividades em educação permanente e avaliaçáo sistemática do cotidiano da equipe, são consideradas como importantes dispositivos para o redelineamento do trabalho (GRANDO; DALL'AGNOL, 2010) e representam um instrumento para a articulação entre os membros da equipe, no intuito de estabelecer o cuidado mais integral aos usuários dos serviços de saúde, pois possibilitam a compreensão da situação mais global dos usuários e das trocas disciplinares. É nessa prática que os profissionais envolvidos no caso constroem a intervenção coletiva, tomam medidas, modificam condutas e conhecem os aspectos sociais e familiares da vida do usuário, dentre outros aspectos. Assim, os profissionais se aproximam ainda mais dos sujeitos atendidos (MATOS; PIRES, 2009).

Além dos profissionais da equipe, as açóes da terapia ocupacional têm buscado um relacionamento mais próximo com os demais setores que apoiam o cuidado à saúde; tais açốes se referem aos encaminhamentos, referência e contrarreferência. Segundo Maeda (2002), a referência é representada por meio do encaminhamento do usuário para um local de maior especialização, tais como os hospitais e clínicas especializadas; diversamente, a contrarreferência está relacionada com o encaminhamento do usuário para serviços de saúde de menor complexidade, tais como os serviços da APS.

A partir da lógica da integralidade da atenção, entende-se que o processo de encaminhamento, de referência e de contrarreferência deve ser considerado fundamental para sua consolidação. Mas, ainda, são observadas questôes relacionadas à dificuldade de articulação dos serviços de referência e contrarreferência dos sistemas de saúde com os demais recursos intersetoriais (REIS et al., 2012).

No discurso coletivo apresentado a seguir, é possível observar que as açóes da terapia ocupacional têm sido pautadas pelo modelo técnico-assistencial de referência, encaminhamentos e contrarreferência.

Realizo o referenciamento para outros serviços de saúde por meio da guia de referência ou por meio de encaminhamento ao médico, para que ele faça tal referenciamento; quanto necessário faço um relatório descritivo. Já os encaminhamentos, realizo dentro do serviço através dos agentes comunitários, por telefone, ou mesmo pessoalmente; quando pessoalmente, procuro os profissionais no serviço, mesmo que não seja por meio de reuniōes ou documentos formais (participantes do DSC).

O discurso permite inferir que as açóes no âmbito do encaminhamento, da referência e da contrarreferência, norteiam as açôes do terapeuta ocupacional; porém, nesta última ação, nota-se que, quando esta depende de outros profissionais do sistema de saúde, há uma dificuldade na organização e na gestão desse processo de trabalho.

Nesse sentido, atualmente, os modelos assistenciais centrados no atendimento das necessidades de saúde da população têm requerido mudanças no processo de produção do cuidado e no modelo de gestáo do trabalho (PIMENTA, 2012). Assim, a produção da saúde implica formatos institucionais que articulam respostas macro e microinstitucionais (MERHY; CECÍLIO, 2003), ou seja, para equacionar o caminhar na linha de cuidado, ordena-se tanto o processo de trabalho em saúde, quanto às demandas de organizaçáo do sistema de saúde e suas interfaces.

Considerando-se o exposto, as ações da terapia ocupacional, nesse sentido, visam a contribuir na gestâo, na construção da linha de cuidado e no processo saúde-doença. Como mostrado no discurso coletivo a seguir, as açôes acontecem de maneira indireta e as atividades propostas envolvem trabalho em equipe, com finalidade de acolhimento e humanização do serviço, com quebra de paradigmas, em que a população deixa de entender os serviços de APS como um espaço curativo e passa a compreender como um espaço comunitário, potente de trocas e fortalecimento de vínculo com a equipe, no qual se promove saúde e se previnem doenças.

Em uma lógica de "gestão participativa", contribuo e colaboro, mesmo que indiretamente, no desenvolvimento do serviço, construção de projetos e organização das açôes. Ainda, algumas participaçôes ocorreram em conjunto com a coordenação, seja para fins de comemoração festiva ou planejamento de açôes como "o dia da vacinação" ou "dia do idoso". Ainda, no contexto que estou, identifico uma necessidade urgente de capacitação e discussão entre os profissionais. A superação da lógica reducionista, fragmentada, curativa e médico-centrada é um desafio em todo o Pais. Aqui a discussão parece ainda sutil e recente; sendo assim, considero como um grande desafio a superação desta lógica na gestão e nas açōes de saúde, educação e assistência social (entre outros) neste contexto (participantes do DSC). 
Considerando-se, entáo, os cuidados na gestão como um processo que está diretamente relacionado com o cuidado às necessidades de saúde da população, Malta e Merhy (2010) apontaram a linha de cuidado como um processo desenhado, também, no campo da gestão, no qual se devem articular intervençôes nos determinantes sociais e em medidas de regulação e legislação, equacionando-se tecnologias, instrumentos, dentre outros, capazes de impactarem o processo saúde-doença.

\subsubsection{Ações no território}

As açóes no território buscam compreender melhor as necessidades da populaçáo assistida e possibilita a construção de redes. Nas ações de diagnóstico territorial, o terapeuta ocupacional tem se voltado para esse âmbito com o intuito de compreender o contexto em que vivem os sujeitos e suas famílias, e o olhar da equipe frente a essa demanda. A pesquisa apontou ainda que as açóes de diagnóstico territorial acontecem de maneira isolada pelo terapeuta ocupacional; assim, é possível refletir e elencar questóes necessárias para maior eficiência na produção da linha de cuidado.

Pode-se observar no discurso coletivo que as características do processo de trabalho, segundo a Política Nacional de Atenção Básica (PNAB) (BRASIL, 2012), corroboram com as açóes da terapia ocupacional no município, na medida em que os terapeutas ocupacionais realizam o levantamento de demanda e necessidade de saúde, buscam conhecer o território em que está inserido e identificam os grupos mais vulneráveis, para então propor suas intervençóes. No discurso coletivo, foi afirmado que:

Para realizar o levantamento de demanda $e$ necessidade de saúde dos usuários, eu peço auxilio aos profissionais da Unidade - principalmente a equipe de enfermagem - e construo um questionário de perfil sociodemográfico e de saúde; assim, duas vezes na semana realizo visitas nas casas dos idosos que fazem parte da área de abrangência. Com os dados obtidos, analiso e levanto as maiores demandas e necessidades desta população. Busco garantir acolbimento e atendimento aos grupos mais vulneráveis que muitas vezes apresentam dificuldade de acesso ao serviço (participantes do DSC).

Esse processo de diagnóstico territorial, segundo o discurso coletivo, acontece, também, a partir de um método de planejamento em saúde denominado Estimativa Rápida Participativa (ERP). Esse método apoia o planejamento participativo, no sentido de contribuir para a identificação das necessidades de saúde de grupos distintos, inclusive daqueles menos favorecidos, a partir da própria população e em conjunto com os administradores de saúde. Ainda, propicia a identificaçáo das condiçôes de vida da população e a maneira como esta se distribui pelo território (BRASIL, 2013). No discurso coletivo, os terapeutas ocupacionais afirmam que:

O processo do diagnóstico territorial é realizado de forma geral e especifica a partir do método da "estimativa rápida e participativa". No levantamento geral realizo uma investigação no município, sejam por meio de pesquisas virtuais elou em campo, relativos à organizaçâo, equipamentos, necessidades, entre outros. Já o levantamento especifico, realizo nos campos especificos de estágio, de forma continua, ampliando e fortalecendo a cada semestre (participantes do DSC).

Compreende-se que as açôes da terapia ocupacional durante o diagnóstico territorial são pautadas em questóes em que se consideram o sujeito, o ambiente e a equipe, levando em conta e elencando acolhimento a grupos vulneráveis e utilizando, para essa análise territorial, métodos específicos que embasam suas açóes.

Além das açôes da terapia ocupacional apontadas no diagnóstico territorial, existem também aquelas voltadas para construçáo de redes, com vista na intersetorialidade como meio para o cuidado integral à saúde. Segundo Monnerat e Souza (2011), a intersetorialidade se volta para a construçáo de interfaces entre diferentes setores e instituiçóes, sejam governamentais ou não, com vista no enfrentamento de problemas sociais complexos que ultrapassem a alçada de um só setor de governo ou área de política pública. Assim, a intersetorialidade tem sido pensada como uma estratégia fundamental para atuar sobre problemas estruturais da sociedade e que incidem sobre o processo saúde-doença.

Nessa perspectiva, pode-se observar que a TO, no intuito de favorecer a construçáo de redes e, por consequência, a atenção à saúde da população atendida, tem tido suas açốes voltadas ao acionamento de outros equipamentos da comunidade. Tal questão é apontada no discurso coletivo a seguir, no qual é relatado que:

Aciono outros equipamentos de diferentes esferas de atenção. Articulo com a comunidade (clube de mãe, vizinhos e moradores, centros espíritas); com equipamentos da saúde (CAPS, SAMU, UBS e USF, ambulatório, Clínica, Programa melhor em casa), serviços da assistência social, cultura, lazer, transporte e segurança, além de centro de apoio pedagógico ao deficiente visual, CEMEA, 
grupo comunitário, entre outros. Ainda, a partir da comunicação que tive com a comunidade foi possivel estreitar o relacionamento com o responsável pelo espaço físico, vizinho da Unidade. Este movimento aproximou a comunidade do serviço de saúde e abriu mais um espaço para o desenvolvimento das açôes da USF na comunidade e participação social (participantes do DSC).

A facilidade das açôes da terapia ocupacional voltadas para construção de redes a partir da intersetorialidade pode ser justificada por congregar, desde o início de sua formação, conhecimentos de várias disciplinas e profissôes, tornando-se, então, uma área do conhecimento e uma profissão interdisciplinar. Assim, o terapeuta ocupacional se constitui como um elemento importante na construção de novos rumos para a atenção à saúde, integral, globalizante, e na perspectiva da totalidade, da subjetividade e da singularidade das pessoas (MEDEIROS, 2003).

Pensando-se na integralidade da assistência em consonância com a intersetorialidade e possibilitando a construção de redes, Carvalho (2012) aponta que o terapeuta ocupacional possui características que favorecem sua inserção no atual sistema público de saúde, pois a preocupação com a visão integral dos sujeitos e o reconhecimento da dimensão social da saúde sempre estiveram presentes na profissão.

\subsection{Consequências dessas ações}

Como resultado dessas açôes, foi possível observar no discurso coletivo que o terapeuta ocupacional ganhou reconhecimento por parte da equipe e da população; construiu, a partir da comunicação com a comunidade, um novo espaço para realização das ações; passou a receber encaminhamentos assertivos com sua prática, e conseguiu a valorização das ocupaçóes e atividades significativas como necessidade de saúde.

No discurso coletivo, os terapeutas ocupacionais apontaram que:

Os encaminhamentos por outros profissionais têm sido mais assertivos e frequentes pela equipe de forma geral. Além dos encaminhamentos realizados pelos ACS, fisioterapeuta e assistente social, tem sido feito, também, pelo clínico geral da UBS e os demais profissionais da equipe da residência. Tais encaminhamentos são realizados de forma verbal ou encaminhados por meio de uma lista. Ainda, os usuários passaram a compreender a importância $e$ os beneficios que a terapia ocupacional pode trazer a eles e a solicitar atendimento na UBS. Profissionais que antes desconheciam a profissão passaram a valorizá-la e, ainda, a me procurar a fim de encaminhar pacientes, deixando claro em seus relatos a importância de ter terapeutas ocupacionais na rede (participantes do DSC).

Segundo Carvalho (2012), entre as profissóes da saúde, o reconhecimento pode ser observado pela valorização das áreas de conhecimento tradicionais e das modernamente ligadas à tecnologia. Por isso, as características da profissão têm tido valor restrito e suas práticas e estratégias de intervenção ainda são pouco compreendidas. Segundo Medeiros (2003), o papel social de uma profissão da saúde também permeia as condiçóes política e econômica ditadas pelas indústrias médicas. E seu reconhecimento é visto como uma questão importante, pois se relaciona com a identidade construída socialmente (CARVALHO, 2012).

Considera-se, então, que o reconhecimento por parte da equipe e da populaçáo tem sido uma resposta positiva para as açóes da TO nesse campo de intervenção, visto que esse reconhecimento tem acontecido por parte da equipe e da populaçáo, possibilitando, então, a construção social da identidade deste profissional. Mas não se deve, apenas, se deixar levar por essas questôes; a falta de reconhecimento do terapeuta ocupacional se deve, também, à falta de participação deste profissional nos setores políticos, em vista de otimizar as açóes e possibilitar maiores aberturas de campo para sua atuação.

Ainda, no discurso coletivo apresentado a seguir, foi relatado que os sujeitos envolvidos nas açōes da TO, seja por atendimento direto ou por participação na equipe, passaram a compreender e valorizar as ocupaçôes e atividades significativas como necessidade de saúde. "Considero como dificuldade vencida a identificação de necessidades de saúde relacionada às ocupaçôes e atividades significativas, ajudando a superar o olhar para as patologias e demandas reducionistas" (participantes do DSC).

Esse relato do sujeito coletivo é coerente com o elencado por Crepeau et al. (2011), em que a autora descreve que, na TO, a ocupação está associada à saúde e ao bem-estar, tanto como um meio quanto como um fim. As escolhas ocupacionais pessoais e da sociedade têm consequências boas e más. Para chegarmos a compreender a ocupação, precisamos reconhecer a amplitude das escolhas ocupacionais e seus efeitos sobre os indivíduos e o próprio mundo.

Assim, compreende-se que a valorização das ocupaçôes e atividades significativas como necessidades de saúde é um ganho importante para atuação da TO nesse campo de intervenção. Observa-se que, pautados nos princípios da profissão e suas atuaçôes, os terapeutas ocupacionais participantes da amostra 
desta pesquisa têm conseguido demonstrar à equipe o impacto das ocupaçôes na saúde dos sujeitos.

\section{Considerações finais}

Entende-se, portanto, que a produção da linha do cuidado à saúde do idoso na TO se dá por meio de diversas açôes, sejam estas com a população, com a equipe ou no território. Tais açôes são permeadas pelos princípios de equidade, integralidade, intersetorialidade e raciocínio clínico em $\mathrm{TO}$, e vão ao encontro com aquelas preconizadas pelo SUS.

Assim, a inserção de terapeutas ocupacionais na APS contribui para a produção do cuidado, se tornando, então, essencial para Saúde Pública. Ainda, suas açóes produzem eficácia nos serviços de APS e contribuem para a diminuição dos custos com a saúde nos demais setores do SUS. É promovido, pelas especificidades desse profissional, o bem-estar e melhores condiçóes da capacidade funcional da população idosa, seja através das ações diretas com a população ou por meio das açóes no território ou com a equipe.

Nos discursos do sujeito coletivo, foram apontadas questôes referentes aos desafios que os profissionais de TO encontram em sua prática na APS, entre as quais foi elencada a falta de terapeutas ocupacionais. Assim, propóe-se a contratação desse profissional para melhor efetivação dessas açóes. Em consonância com o descrito, destaca-se que o objetivo deste trabalho não foi esgotar as ações da TO na APS, mas sim deixar uma reflexão acerca dessas ações, compreendendo sua relevância nos serviços de APS.

\section{Referências}

BITTAR, C.; LIMA, L. C. V. O impacto das atividades em grupo como estratégia de promoçáo da saúde na senescência. Revista Kairós Gerontologia, São Paulo, v. 14, n. 4, p. 101-117, 2011.

BRASIL. Ministério da Saúde. Portaria GM 154 de 24 de janeiro de 2008. Cria os Núcleo de Atenção Integral à Saúde da Família - NASFs. Diário Oficia [da] República Federativa do Brasil, Brasília, DF, 24 jan. 2008a.

BRASIL. Ministério da Saúde. Diretrizes e recomendaçôes para o cuidado integral de doenças crônicas não transmissíveis: promoção da saúde, vigilância, prevenção e assistência. Brasília, 2008b.

BRASIL. Ministério da Saúde. Diretrizes do NASF: Núcleo de Apoio a Saúde da Família. Brasília, 2009.

BRASIL. Ministério da Saúde. Portaria no 4.279, de 30 de dezembro de 2010. Estabelece diretrizes para a organização da Rede de Atenção à Saúde no âmbito do Sistema Único de Saúde - SUS. Diário Oficial [da] Re- pública Federativa do Brasil, Brasília, DF, 31 dez. 2010. Disponível em: <http://bvsms.saude.gov.br/bvs/saudelegis/gm/2010/prt4279_30_12_2010.html>. Acesso em: 25 jul. 2013.

BRASIL. Ministério da Saúde. Politica Nacional de Atenção Básica - PNAB. Brasília, 2012. Disponível em: <http://189.28.128.100/dab/docs/publicacoes/geral/ pnab.pdf>. Acesso em: 25 jul. 2013.

BRASIL. Ministério da Saúde. Saúde e cidadania: estimativa rápida participativa. Disponível em: $<$ http://portalses.saude.sc.gov.br/arquivos/sala_de_leitura/saude_e_ cidadania/extras/apres.html>. Acesso em: 25 jul. 2013.

CARVALHO, C. R. A. A Identidade profissional dos terapeutas ocupacionais: consideraçôes a partir do conceito de estigma de Erving Goffman. Saúde e Sociedade, São Paulo, v. 21, n. 2, p. 364-371, 2012. http://dx.doi. org/10.1590/S0104-12902012000200010.

CONSELHO FEDERAL DE FISIOTERAPIA E TERAPIA OCUPACIONAL - COFFITO. Decreto lei n. 938 - De 13 de outubro de 1969. Provê sobre as profissóes de fisioterapeuta e terapeuta ocupacional, e dá outras providências. Diário Oficial [da] República Federativa do Brasil, Brasília, DF, 14 out. 1969. Disponível em: <http://www.coffito.org.br/site/index.php/terapia-ocupacional/regulamentacao.html >. Acesso em: 10 ago. 2013.

CREPEAU, E. B.; COHN, E. S.; SCHELL, B. A. B. Willard \& Spackman: terapia ocupacional. Rio de Janeiro: Guanabara Koogan, 2011.

DALL'AGNOL, C. M.; MARTINI, A. C. Reuniôes de trabalho: mais que uma ferramenta administrativa, um processo educativo. Texto \& Contexto Enfermagem, Florianópolis, v. 12, n. 1, p. 89-96, 2003.

FRANCO, T. B.; MAGALHÃES JUNIOR, H. A integralidade e as linhas de cuidado. In: MERHY, E. E. et al. O Trabalho em saúde: olhando e experienciando o SUS no cotidiano. São Paulo: Hucitec, 2003. p. 1-10.

GALHEIGO, S. M. Terapia ocupacional, a produção do cuidado em saúde e o lugar do hospital: reflexóes sobre a constituição de um campo de saber e prática. Revista de Terapia Ocupacional da Universidade de São Paulo, São Paulo, v. 19, n. 1, p. 20-28, 2008. http://dx.doi. org/10.11606/issn.2238-6149.v19i1p20-28.

GARCIA, M. A. A. et al. Idosos em cena: falas do adoecer. Interface: Comunicação, Saúde, Educação, Botucatu, v. 9, n. 18, p. 537-552, 2005.

GORDON, D. M. A história da terapia ocupacional. In: CREPEAU, E. B.; COHN, E. S.; SCHELL, B. A. B. Willard \& Spackman: terapia ocupacional. Rio de Janeiro: Guanabara Koogan, 2011. p. 204-217.

GRANDO, M. K.; DALL'AGNOL, C. M. Desafios do processo grupal em reuniōes de equipe da estratégia saúde da família. Escola Anna Nery, Rio de Janeiro, v. 14, n. 3, p. 504-510, 2010. http://dx.doi.org/10.1590/S141481452010000300011 . 
INSTITUTO BRASILEIRO DE GEOGRAFIA E ESTATÍSTICA - IBGE. Coordenação de população e indicadores sociais: informaçóes sobre os municípios brasileiros. Disponível em: <http://cidades.ibge.gov.br/xtras/perfil. php?lang=\&codmun=317010>. Acesso em: 2 nov. 2013.

LACERDA, M. R. et al. Atenção à saúde no domicílio: modalidades que fundamentam sua prática. Saúde e sociedade, São Paulo, v. 15, n. 2, p. 88-95, 2006. http:// dx.doi.org/10.1590/S0104-12902006000200009.

LEFÉVRE, F.; LEFÉVRE, A. M. C. O sujeito coletivo que fala. Interface - Comunicação, Saúde, Educação, Botucatu, v. 10, n. 20, p. 517-524, 2006. http://dx.doi. org/10.1590/S1414-32832006000200017.

MAEDA, S. T. Gestäo da referência e contra-referência na atenção ao ciclo grávido puerperal: a realidade do Distrito de Saúde do Butantã. 2002. 185 f. Tese (Doutorado em Enfermagem) - Escola de Enfermagem da Universidade de São Paulo, São Paulo, 2002.

MALTA, D. C.; MERHY, E. E. O percurso da linha do cuidado sob a perspectiva das doenças crônicas náo transmissíveis. Interface: Comunicação, Saúde, Educação, Botucatu, v. 14, n. 34, p. 593-605, 2010.

MATOS, E.; PIRES, D. E. P. Práticas de cuidado na perspectiva interdisciplinar: um caminho promissor. Texto e Contexto Enfermagem, Florianópolis, v. 18, n. 2, p. 338-346, 2009. http://dx.doi.org/10.1590/S010407072009000200018 .

MEDEIROS, M. H. R. Terapia ocupacional: um enfoque epistemológico e social. São Paulo: Hucitec, 2003.

MERHY, E. E.; CECÍLIO, L. C. O. A integralidade do cuidado como eixo da gestão hospitalar. Campinas: Unicamp, 2003.

MONNERAT, G. L.; SOUZA, R. G. Da seguridade social à intersetorialidade: reflexōes sobre a integração das políticas sociais no Brasil. Revista Katálysis, Florianópolis, v. 14, n. 1, p. 41-49, 2011.

NEISTADT, M. E. Introdução à avaliação e entrevista. In: CREPEAU, E. B.; CONH, E. S.; SCHELL, B. A.
B. Willard \& Spackman: terapia ocupacional. São Paulo: Click Books, 2008. p. 137-152.

PIMENTA, A. L. A construção de colegiados de gestão: a experiência de gestáo da Secretaria Municipal de Saúde analisada por um ator político implicado. Saúde e Sociedade, São Paulo, v. 21, n. 1, p. 29-45, 2012. http:// dx.doi.org/10.1590/S0104-12902012000500003.

REIS, F.; GOMES, M. L.; AOKI, M. Terapia ocupacional na Atenção Primária à Saúde: reflexôes sobre as populações atendidas. Cadernos de Terapia Ocupacional da UFSCar, São Carlos, v. 20, n. 3, p. 341-350, 2012. http://dx.doi.org/10.4322/cto.2012.034.

ROCHA, E. F.; SOUZA, C. C. B. X. Terapia ocupacional em reabilitação na Atençáo Primária à Saúde: possibilidades e desafios. Revista de Terapia Ocupacional da Universidade de São Paulo, São Paulo, v. 22, n. 1, p. 3644, 2011. http://dx.doi.org/10.11606/issn.2238-6149. v22i1p36-44.

SCHELL, B. B. Raciocínio clínico: a base da prática. In: CREPEAU, E. B.; COHN, E. S.; SCHELL, B. A. B. Willard \& Spackman: terapia ocupacional. São Paulo: Click Books, 2008. p. 80-90.

SILVA, Z. P. et al. Perfil sociodemográfico e padrão de utilizaçấo dos serviços de saúde do Sistema Único de Saúde (SUS), 2003- 2008. Ciência e Saúde Coletiva, Rio de Janeiro, v. 16, n. 9, p. 3807-3816, 2011. http:// dx.doi.org/10.1590/S1413-81232011001000016.

WITT, R. R. Competências da enfermeira na atençäo básica: contribuição à construção das funções essenciais de saúde pública. 2005. 336 f. Tese (Doutorado em Enfermagem em Saúde Pública) - Escola de Enfermagem de Ribeirão Preto, Ribeirão Preto, 2005.

WORLD HEALTH ORGANIZATION - WHO. Envelhecimento ativo: uma política de saúde. Brasília: Organização Pan-Americana da Saúde, 2005. Disponível em: $<$ http://www.prosaude.org/publicacoes/diversos/envelhecimento_ativo.pdf>. Acesso em: 9 ago. 2013.

\section{Contribuição dos Autores}

Cassio Batista Alves: elaboração do projeto, coleta e análise dos dados e redação do artigo final. Grasielle Silveira Tavares Paulin: orientação da elaboração do projeto, coleta e análise dos dados e redação do artigo final.

\section{Notas}

${ }^{1}$ O estudo foi submetido ao Comitê de Ética em Pesquisa em Seres Humanos da Universidade Federal do Triângulo Mineiro (UFTM) e aprovado pelo protocolo n. ${ }^{\circ}$ 2457/2013. Todos os participantes assinaram o Termo de Consentimento Livre e Esclarecido (TCLE) e aceitaram a realização das transcrições dos dados. 